\title{
A UNIFIED SYSTEM FOR DISTRIBUTING AND RETRIEVING INFORMATION FOR A MULTILEVEL HIERARCHY OF USERS IN AN INSTITUTION
}

\section{Igor Cherevko}

Yuriy Fedkovych Chernivtsi National University, Ukraine

\section{Andriy Pertsov}

Yuriy Fedkovych Chernivtsi National University, Ukraine

OMESTE

JEL Category: $\mathbf{1 2 3}$

\begin{abstract}
This article presents a specific model of the distribution of the messages and retrieving information for a multilevel hierarchy of users that was recently proposed by the authors. The main channels and messengers of communication between users were analyzed and compared. A Telegram messenger bot has been developed to automate the sending of information messages, divided into hierarchical levels of recipients in educational institutions. C\# programming language and .NET Core technology, Entity Framework Core, ASP.NET Web API Core, PostgreSQL database were used for development. They are implemented in the VisualStudio environment appropriate application in the form of a web application API.
\end{abstract}

Keywords: communications, education systems

\section{INTRODUCTION}

Today's society is characterized by the global use of information technology, which is seen as a means of improving the effectiveness of professional and educational activities. An important feature of our time is the rapid development of Internet technologies and their use in all areas of activity.

Address of the corresponding author: Igor Cherevko 邦i.cherevko@chnu.edu.ua
The availability of computers and smartphones has been the impetus for the development of new communications services. Telephone calls have been replaced by online voice and even video calls. People started using computers and the Internet to communicate. The first tool for this was email, which ideologically followed traditional letters, but was much more effective. Next, chats became popular. They were used for group communication between two or more users. It is much easier for the average user to write a text message and find out what they are interested in online. Messenger does not force an instant reply, and therefore it is more convenient for a person to reach out. 
The emergence of messenger programs has caused a certain revolution in messaging, and the important role here is played by bots - special programs that execute certain commands automatically or according to a given algorithm. Chatbots can simulate user communication with one or more callers. Such virtual interlocutor can be developed even without the involvement of programmers. The basic idea of using chatbots is to automate repetitive processes and interactive communication with the user. Bots are designed to assist the user in achieving their goal (regularly receiving useful information, setting reminders, etc.).

In this paper, a Telegram Messenger bot has been developed to automate the sending of hierarchical recipient-level information messages. The main purpose of the developed bot is to create a unified system through which users can subscribe to receive information messages and, depending on the role, send them to other users.

The Telegram messenger bot developed in this work consists of two parts: a web application for receiving and processing user messages and a database. The following modern technologies were used to implement the bot: .NET Core, Entity Framework Core, ASP.NET Web API Core, PostgreSQL database, and Visual Studio 2017 programming environment, which provide a high level of development of modern information systems of various sizes and complexity. The bot supports three commands: registering a new user, selecting recipients to send a new informational message, and sending feedback to the administrator. The bot lets you send messages to a specific group of users, manage registered users, set user rights by role, provides an interface for sending messages to a select group of people.

\section{LITERATURE REVIEW}

The main goal of modernization in the sector of education in the world is the achievement of the new quality of learning process that would correspond to new socio-economic conditions. This requires an effective organization of the educational process. Also important is the development of students' skills of the XXI century, which would be useful in their future professional activity. Society puts new demands forward for the young people, such as to be able to cooperate, to work effectively both individually and in a team, so it becomes necessary to develop students' skills of modern information technologies usage. Note that the detailed analysis in terms of expanding communication space of globalized society, a transformation of the old, and the emergence of new practices of social interaction in different spheres of society is in the work (Pinchuk, 2015).

This approach provided in the Strategy of Information Society Development in Ukraine for 2013-2020 (2013), the National Strategy of Education Development in Ukraine for the period up to 2021 (from 25.06.2013 № 344/2013) (2013), and the Law on Higher Education (2014).

In the modern world becoming more and more popular the use of networks in education. Among a variety of networks, social networks, which reflect a diversity of people relationships, are a priority (Kolaczyk, 2009; Kosinski et all, 2015; Horkovenko, 2017; Hubanov, Novikov, \& Chshartishvili, 2010; Nosova, \& Sennikova, 2014; Goetz at all, 2009). The study of social networks is important since it helps understanding how our world is organized, what place each of us takes in it, how this situation affects us and how the knowledge can be used to achieve our goals. In recent years, new technologies appear for data and knowledge organization to rationalize social life.

Lately, many models of information distribution in social networks have been considered. In Bamba, Pasichnyk, Kunanets, and Turbal (2018A, 2018B) there was proposed a new approach to modeling the process of opinion spreading in a social group based on the procedures that resemble the process that reminiscent of transferring excitation in the nerve cell.

This paper examines the problem of analyzing and comparing Internet communication channels in general and existing Internet messengers (Statista, 2020; AIN, 2019; \& Statista, 2016). A Telegram messenger bot has been developed to automate the sending of hierarchical recipientlevel information messages, which is used at the Chernivtsi National University by the Faculty of Mathematics and Informatics (Send API, Messenger Platform, Viber REST API, Bots FAQ, and Telegram Bot $\mathrm{API})$. C\# programming language and .NET Core technology, Entity 
Framework Core, ASP.NET Web API Core, PostgreSQL database were used for development. They are implemented in the Visual Studio environment appropriate application in the form of a web API (Freeman, 2018; Lock, 2018).

\section{PROBLEM STATEMENT}

There are currently quite a few information sources available at the university where students, faculty, and other staff can receive information:

- University website;

- Faculty website;

- Department website;

- Teacher's personal page;

- Curator's messages;

- Student union announcements.

Usually, each of these sources is placed on a separate website, which makes it difficult to receive timely information from all of them. Due to a large number of resources, there may also be a problem receiving notifications of new messages that may need to be responded to as soon as possible.

On the other hand, there is no common way to distribute information to different users. For each of the information sources above, you need to have separate access to add news to it.

Creating a bot for the Internet messenger aims to solve these problems by creating a unified system for information distribution and retrieval. At the same time, support for a multi-level hierarchy of users will allow sending messages only to a specific group of people, and for recipients - to receive only the information that is addressed to them, without any excess. And since Internet messenger is an instant messaging service, all recipients are guaranteed to be notified of new information as soon as possible.

\subsection{Internet communication channels. Characteristics and comparison.}

Today there are many different channels of communication on the Internet:

- video and audio;

- website;

- Email;

- Messenger.

Consider the following characteristics:
- Convenience/efficiency in mass communication

- Individual communication convenience/ efficiency

- Speed of obtaining information

- determining the level of importance for the recipient.

For video and audio communication channels, it is quite difficult to synchronize free time among all recipients, especially if there are many of them, which complicates the distribution of information in this way. On the other hand, when making an individual call, we are guaranteed to bring information to the recipient if they pick up the handset, but they do not have the opportunity to determine the content of the call in advance and decide its importance.

It is very easy for websites to publish information to the mass media, but for individuals, it forces users to register on this website. Also, end-user information will require you to know the address of the webpage of the website where the information is posted and to periodically visit it to check for updates.

Email, unlike the previous two channels, makes it easy to distribute information to each user individually and to groups of users at the same time. However, the speed of information retrieval by users can be reduced due to a large amount of information from other resources and spam.

Table 1. Channels of communication. Comparison.

\begin{tabular}{|c|c|c|c|c|}
\hline Name & 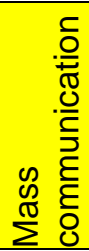 & 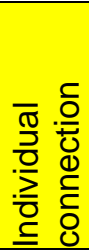 & 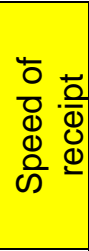 & 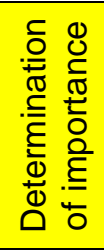 \\
\hline Video / Audio & - & + & + & - \\
\hline Website & + & - & - & + \\
\hline Email & + & + & - & + \\
\hline Messenger & + & + & + & + \\
\hline
\end{tabular}

Internet messengers are very similar to e-mail in their characteristics, but eliminating its disadvantage - usually, messages from the messenger are automatically filtered from spam and used mostly for a personal exchange of information, which improves the speed of its receipt and user's response. As with email, every recipient has the opportunity to read the 
information at a convenient time after receiving a notification of its presence.

Table 2. Features of messengers. Comparison table.

\begin{tabular}{|c|c|c|c|c|}
\hline Name & 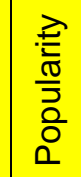 & Capacity & 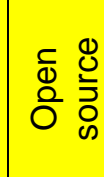 & 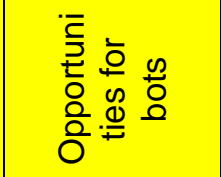 \\
\hline $\begin{array}{l}\text { Facebook } \\
\text { Messenger }\end{array}$ & № 1 & $\begin{array}{l}200 \\
\text { requests/ } \\
\text { user }\end{array}$ & No & $\begin{array}{l}\text { 20 methods } \\
\mathrm{API}+\mathrm{UI}\end{array}$ \\
\hline Viber & № 2 & $\begin{array}{l}500 \\
\text { requests }\end{array}$ & No & $\begin{array}{l}\text { 15 } \text { methods } \\
\text { API, without } \\
\text { UI }\end{array}$ \\
\hline Telegram & № 3 & $\begin{array}{l}30 \\
\text { requests }\end{array}$ & Yes & $\begin{array}{l}\text { 80 methods } \\
\mathrm{API}+\mathrm{UI}\end{array}$ \\
\hline WhatsApp & № 4 & & No & $\begin{array}{l}\text { There is no } \\
\text { support for } \\
\text { bots }\end{array}$ \\
\hline Skype & № 8 & $\begin{array}{l}10 \\
\text { requests }\end{array}$ & No & $\begin{array}{l}\text { Microsoft Bot } \\
\text { API }\end{array}$ \\
\hline
\end{tabular}

In analyzing and comparing popular messengers, we will consider the following characteristics:

- Popularity

- Bandwidth

- The open-source protocol used

- The ability to create a bot

- The ability to add user interface elements to the created bot.

Messenger popularity will use their position in the ranking of mobile applications by the number of downloads among all free applications in the Communication category. As most of the population in Ukraine use mobile phones running Android, the popularity data can be viewed in the Google Play mobile application directory.

\section{DESCRIPTION OF SOFTWARE PRODUCT}

The project in the application implements the bot for the Telegram Internet messenger in the form of the RESTful API web application. After receiving a message from the user, the bot processes it appropriately, communicates with the remote database if needed, and sends a reply via Telegram back to the user.

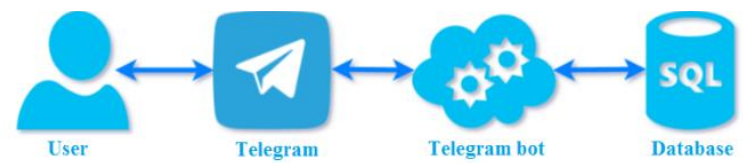

Figure 1. Scheme of user interaction with the bot.

The project is written in C\# programming language in Visual Studio 2017 with the use of .NET Core technology to run a web application on Windows, macOS, and Linux

The database uses Entity Framework Core ORM technology to automatically create all the entities used in the code in the database. It is possible to immediately fill the database with the required values and, if necessary, simply change the database type by connecting the appropriate Entity Framework provider.

Bot features:

- $\quad$ send messages to a specific group of users

- managing registered users

- setting user rights by role

- providing an interface for sending messages to a select group of people.

Bot commands:

- /start - register a new user

- /send - select recipients and send a new informational message

- /feedback - send feedback to the administrator

User groups:

- Rector

- Dean

- Head of Department

- teacher

- group leader

- student.

The following information is stored in the database for user identification:

- Unique user ID

- Telegram's unique user ID

- Phone number hash to determine user role

- Password hash (PasswordHasher is used for hashing, which hashes the password using PBKDF2 with HMAC-SHA256, 128-bit salt, 256-bit key, and 64000 iterations)

- User status (whether the user is an admin)

- Place in the hierarchy and role of the user. 


\subsection{Setup and launch}

To run the bot, you must install the NET Core SDK version 2.1.500.

To configure the bot on your computer where it will run, you must set the values for the following environment variables:

- NewsfeedBot.Db - the value of connection string to the database

- $\quad$ "NewsfeedBot.Host" - the value of the server host from which the bot will be accessible on the Internet, through which Telegram will communicate with the bot for transmission of updates

- $\quad$ "NewsfeedBot.TelegramToken" - the value of the Telegram bot token received from @BotFather on whose behalf the bot will operate

You must then start the web server using the following commands from the source folder of the application:

- dotnet restore

- dotnet build

- dotnet run

\subsection{Possible improvements}

The software created has great potential for expanding functionality. For example, it can be supplemented by the following:

- $\quad$ add automatic parsing of news from already existing university information resources and their automatic distribution.

- $\quad$ add integration with the University's e-learning system ("Moodle") to receive and automatically send grades for student submissions and notifications to teachers about new student work.

- add automatic renaming of groups at the end of the school year.

- make it easier for new users to be added to the Admin Interface Database.

- ability to choose from which sources to receive new messages.

- create a mechanism for sending all past messages for the current academic year to users who have registered after sending them.

- create the ability to enter any user roles and set their hierarchy to send messages.

\section{WORKS CITED}

(2013). Strategy for Information Society Development in Ukraine, http://zakon2.rada.gov.ua/laws/show/386.

Bomba, A., Pasichnyk, V., Kunanets, N., \& Turbal, Y. (2018). Mathematical and computer models of message distribution in social networks based on the space modification of the Fermi-PastaUlam approach. Advances in Intelligent Systems and Computing book series (AISC), Vol. 754, pp. 257-266.

Bomba, A., Pasichnyk, V., Kunanets, N., \& Turbal, Y. (2018). Process modeling of message distribution in a social network based on socio-communicative solutions. International journal of computing, 76-88

Bots FAQ. - https://core.telegram.org/bots/faq.

Freeman A. (2018). Pro Entity Framework Core 2 for ASP.NET Core MVC / Adam Freeman. -New York: Apress. -650 p.

Goetz, M., Leskovec, J., Mcglohon, M., \& Faloutsos, C. (2009). Modeling blog dynamics. ICWSM

Horkovenko, D. (2017). Overview of the models of information distribution in social networks. Young scientist 8, 23-28

Hubanov, H., Novikov, D., \& Chshartishvili, A. (2010). Social networks: modeling of information influence, management and confrontation, Springer

Kolaczyk, E.D. (2009). Statistical Analysis of Network Data, Springer Series in Statistics. Springer New York, New York 
Kosinski, M., Matz, M., Gosling, S., Popov, V., \& Stillwell, D. (2015). Facebook as a Research Tool for the Social Sciences: Opportunities, Challenges, Ethical Considerations, and Practical Guidelines. American Psychologist 70(6), 543-556. doi: 10.1037/a0039210.

Leading social networks worldwide as of January 2016, ranked by a number of active users (in millions), http://www.statista.com/statistics/272014/global-social-networks-ranked-bynumber-of-users/.

Leading social networks worldwide as of January 2020 ranked by a number of active users (in millions), https://www.statista.com > Internet > Social Media \& User-Generated Content.

Lock A. (2018). ASP.NET Core in Action. New York: Manning Publications, 712 p.

Messenger Platform - Documentation - Facebook for Developers https://developers.facebook.com/docs/messenger-platform.

Nosova, M., \& Sennikova, L. (2014). Modeling the information dissemination in decentralized network systems with irregular structure. New information technologies and automated systems, 17

Nosova, M., \& Sennikova, L. (2014). Modeling the information dissemination in decentralized network systems with irregular structure. New information technologies and automated systems, № 17

Pinchuk, O. P. (2015). Historical and analytical review of social networking technologies and prospects of their use in training. Information Technologies and Learning Tools, 4(48), 14-34 ,

Send API - Messenger Platform - Documentation - Facebook for Developers https://developers.facebook.com/docs/messenger-platform/reference/send-api/\#limits.

Telegram Bot API. - https://core.telegram.org/bots/api

The Law of Ukraine "On higher education" from 01.07.2014 number 1556-VII, http://zakon4.rada.gov.ua/laws/show/1556-18.

The National Strategy for the Development of Education in Ukraine until 2021, http://zakon4.rada.gov.ua/laws/show/344/2013.

Received for publication: $\quad 06.09 .2020$

Revision received: $\quad 30.11 .2020$

Accepted for publication: $\quad 30.12 .2020$

\section{How to cite this article?}

Style - APA Sixth Edition:

Cherevko, I., \& Pertsov, A. (2021, January 15). A unified system for distributing and retrieving information for a multilevel hierarchy of users in an institution. (Z. Cekerevac, Ed.) MEST Journal, 9(1), 1-7. doi:10.12709/mest.09.09.01.01

Style - Chicago Sixteenth Edition:

Cherevko, Igor, and Andriy Pertsov. 2021. "A unified system for distributing and retrieving information for a multilevel hierarchy of users in an institution." Edited by Zoran Cekerevac. MEST Journal (MESTE) 9 (1): 1-7. doi:10.12709/mest.09.09.01.01.. 
Style - GOST Name Sort:

Cherevko Igor and Pertsov Andriy A unified system for distributing and retrieving information for a multilevel hierarchy of users in an institution [Journal] // MEST Journal / ed. Cekerevac Zoran. - Belgrade - Toronto : MESTE, January 15, 2021. - 1 : Vol. 9. - pp. 1-7.

Style - Harvard Anglia:

Cherevko, I. \& Pertsov, A., 2021. A unified system for distributing and retrieving information for a multilevel hierarchy of users in an institution. MEST Journal, 15 January, 9(1), pp. 1-7.

Style - ISO 690 Numerical Reference:

A unified system for distributing and retrieving information for a multilevel hierarchy of users in an institution. Cherevko, Igor and Pertsov, Andriy. [ed.] Zoran Cekerevac. 1, Belgrade - Toronto: MESTE, January 15, 2021, MEST Journal, Vol. 9, pp. 1-7. 